AROUEOLOGÍA Y SOCIEDAD

№ 26, 2013: 207-228

ISSN: 0254-8062

RECIBIDO: 28 / MAY. / 2013

ACEPTADO: 5 / JUN. / 2013

\title{
AROUEOLOGÍA DE LA CUENCA MEDIA DEL RÍO MAYO, MOYOBAMBA, SAN MARTÍN
}

\author{
Pieter VAN DALen Luna \\ UNIVERSIDAD NACIONAL MAYOR DE SAN MARCOS \\ pvandalen2@hotmail.com \\ CiRILO CORNEJo CONDEÑA \\ UNIVERSIDAD NACIONAL SAN LUIS GONZAGA DE ICA \\ cornelius_24_70@hotmail.com \\ Gina Alarcón HuARAC \\ UNIVERSIDAD NACIONAL SAN LUIS GONZAGA DE ICA \\ gina_23_2005@hotmail.com
}

\section{RESUMEN}

Se presentan los resultados de las investigaciones desarrolladas en la cuenca media del río Mayo, distrito de Moyobamba, departamento de San Martín. Se trata de una región que en diferentes periodos culturales ha tenido desarrollos socio políticos andinos y en otros amazónicos. Por su ubicación, entre el departamento de Amazonas y la Amazonía baja (Tarapoto y Loreto), ha sido punto de tránsito en las interacciones acaecidas entre ambas regiones, amalgamada mediante una compleja red comercial.

A partir de las investigaciones desarrolladas los años 2008 y 2009 se identificó un total de 25 sitios arqueológicos, compuestos mayormente por sitios con dispersión de cerámica y pequeños recintos de planta ovalada, de influencia andina.

Los resultados de estas investigaciones nos muestran una mayor aproximación al entendimiento de las sociedades que poblaron estos territorios antes de la invasión española.

Palabras Clave: Arqueología, Moyobamba, Amazonía, San Martín, río Mayo.

\section{Abstract}

We present the results of the research conducted in the middle basin of the Mayo river, Moyobamba district, department of San Martin. Its a region that has had different cultural periods socio-political developments in other Andean and Amazonian. Its location between the department of Amazonas and the Amazon low (Tarapoto and Loreto), has been a point of transit in the interactions occurring between the two regions, amalgamated by a complex trade network.

From research conducted in 2008 and 2009 identified a total of 25 archaeological sites, sites composed mostly of ceramic dispersion and small enclosures oval plan of Andean influence.

The results of these investigations show a greater approach to understanding societies that inhabited these lands before the Spanish invasion.

KeYwords: Archaeology, Moyobamba, Amazon, San Martin, Mayo River. 


\section{INTRODUCCIÓN}

Moyobamba, en la Amazonía peruana norte, es una de las regiones muy poco investigadas por la arqueología. Es por ello que no se conoce las características de las poblaciones que se desarrollaron en este territorio antes de la llegada de los españoles y del Tawantinsuyu.

El presente artículo está referido a los resultados del Proyecto de Catastro e Identificación de Sitios Arqueológicos desarrollados por Cofopri en el distrito de Moyobamba, cuenca media del río Mayo, entre los meses de octubre de 2008 y marzo de 2009. Como resultado se logró identificar un total de 25 sitios, distribuidos en las categorías de conjuntos arqueológicos con estructuras públicas, sitios domésticos, paisajes culturales arqueológicos, sitios ceremoniales y sitios con dispersión de cerámica. Los datos recuperados son de gran importancia para la comprensión del proceso cultural en esta zona, ya de por sí olvidada por la arqueología. Estos sitios que datan de los periodos tardíos, corresponderían a la entidad político-social que se asentó en estos territorios y que fueron conquistados por el Tawantinsuyu y luego vistos y reducidos por Juan Pérez de Guevara el año 1541, en que llegaron los primeros españoles a la región y realizaron la primera fundación de Moyobamba.

\section{LA CUENCA DEL RÍo MAYo}

El río Mayo (denominado en las crónicas como Mayu), perteneciente a la vertiente hidrográfica del Amazonas, es uno de los ríos más importantes que alimentan al río Huallaga antes que desemboque en el río Marañón. Se origina en el flanco oriental del departamento de Amazonas, al norte de la villa Jumbilla, en la provincia de Bongará, discurriendo en dirección al sureste hasta ingresar al departamento de San Martín por su extremo noroccidental, entre las provincias de Moyobamba y Rioja. Recibe en esta zona a numerosos afluentes semi-torrentosos. Posteriormente discurre por entre la provincia de San Martín (su capital Tarapoto), para desembocar al río Huallaga tras recorrer un cauce de casi $300 \mathrm{~km}$, cerca de la localidad de Shapaja. El Alto Mayo es aquel sector del río ubicado desde su naciente hasta la localidad de Moyobamba, caracterizado por formar un territorio orográfico de tipo andino, pero con abundante vegetación y fauna amazónica. Predominan los suelos arcillosos (de color rojo), con formaciones de roca sedimentaria aislada. El sector medio del Mayo está conformado entre la ciudad de Moyobamba y la ciudad de Tarapoto, desde donde se inicia su sector bajo hasta su desembocadura.

\section{UBICACIÓN DEL ÁREA DE ESTUDIO}

El área motivo de nuestro estudio se encuentra localizado en el sector del Alto Mayo que comprende el distrito de Moyobamba, provincia del mismo nombre, región San Martín, abarcando ambas márgenes del mismo. Sin embargo, cabe señalar que nuestra investigación se limitó al catastro únicamente de áreas cultivables y alrededores, no habiéndose prospectado ni las áreas de conservación municipal, ni terrenos de las comunidades nativas, ni las elevaciones abruptas. El territorio investigado abarca principalmente un territorio llano conformado por el valle mismo y algunas colinas bajas que emergen desde el fondo del valle.

\section{ANTECEDENTES DE ESTUDIO EN LA ZONA}

Existen pocas investigaciones en los alrededores de Moyobamba. El trabajo que nos presenta una visión acerca de algunos sitios arqueológicos, así como los estilos cerámicos de la provincia de Tarapoto es el artículo «Cerámica antigua del Huallaga central» de Ravines (1995: 15-24), quien describe, de manera genérica, un total de ocho sitios arqueológicos ubicados en los alrededores de Tarapoto, definiéndolos como parte de una tradición cultural local. Ravines realiza la tipología de una muestra de material cerámico recolectada superficialmente de estos sitios. Otro trabajo que hace referencia mediante descripciones etnohistóricas a la arqueología de la provincia de Moyobamba es el libro de 
Waldemar Espinoza, Juan Perez de Guevara y la historia de Moyobamba, siglo XVI. Espinoza señala que al momento de la invasión española, este territorio era poblado por tres grupos étnicos, grupos de mediano desarrollo cultural. Son también importantes los trabajos de investigación desarrollados por Anselmo Lozano, quien ha registrado numerosos sitios de la localidad, así como los trabajos que vienen realizando en losúltimos años Esteban García y Liz Saavedra del INC San Martín, quienes vienen identificando numerosos sitios en esta zona.

\section{Metodología DE LA INVESTIGACión}

El catastro arqueológico es un proceso de la arqueología que busca realizar el censo o inventario oficial de los bienes culturales (sean arqueológicos o históricos) de una cuenca o región determinada, la

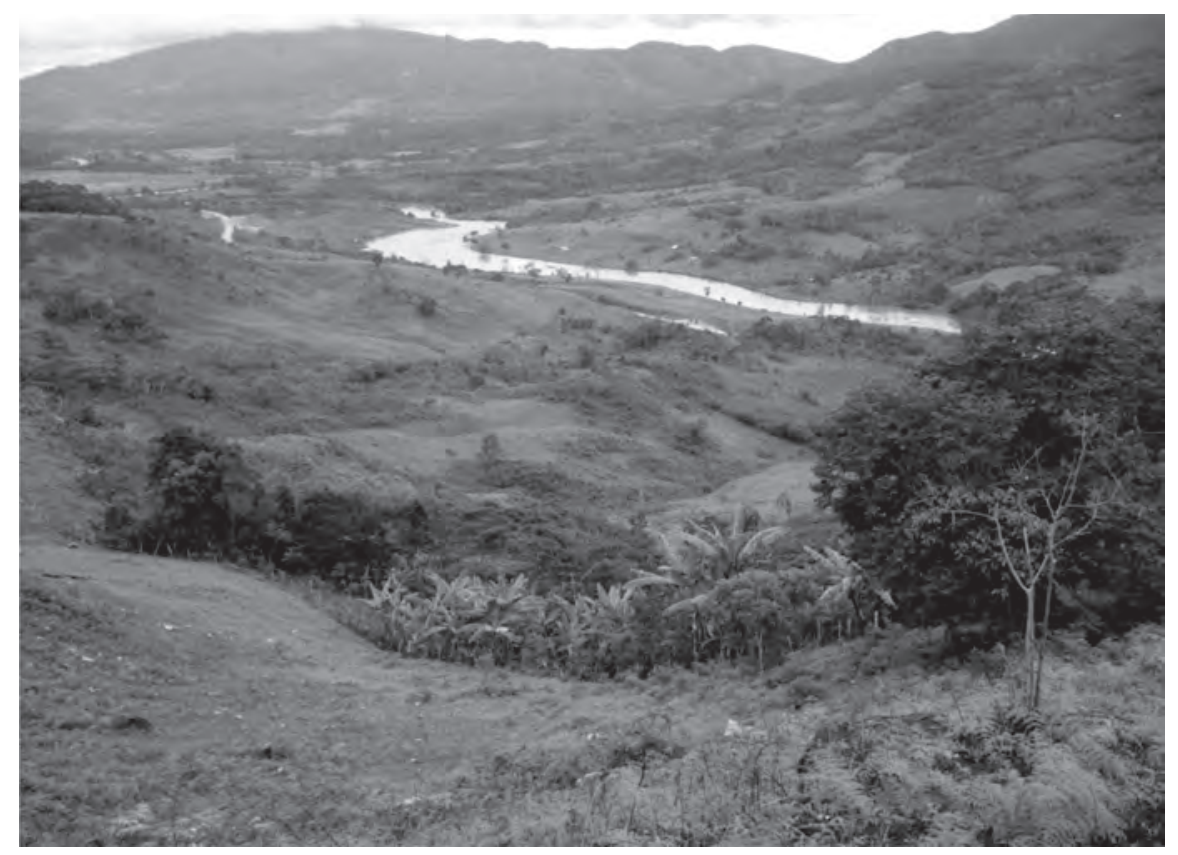

Figura 1. Vista panorámica del cauce medio del río Mayo.

cual se realiza mediante el trabajo prospectivo. El logro final de un catastro arqueológico es el ordenamiento sistemático de la totalidad de elementos patrimoniales previamente inventariados (Milla 1977-78: 41). El catastro arqueológico desarrollado en el distrito de Moyobamba ha seguido cuatro etapas metodológicas bien definidas:

1. Revisión de antecedentes de estudio en el distrito de Moyobamba, en particular y en el departamento de San Martín en general.

2. Estudios cartográficos y fotogramétricos. En esta etapa se trató de identificar mediante el análisis de las cartas nacionales a escala 1:100000 № 11-H-Cachiyacu, 12-H - Villa de Jumbillas, 12-I - Nueva Cajamarca, 12-J - Balsapuerto, 13-I - Rioja, y 13-J - Moyobamba, del Instituto Geográfico Nacional, así como los planos a escalas diversas de Cofopri y las fotos aéreas y satelitales del área de estudio.

3. Prospección arqueológica superficial sin excavaciones.

4. Trabajo de gabinete y procesamiento de datos.

5. Elaboración del informe final y los expedientes técnicos para su declaratoria como Patrimonio Cultural de la Nación. 


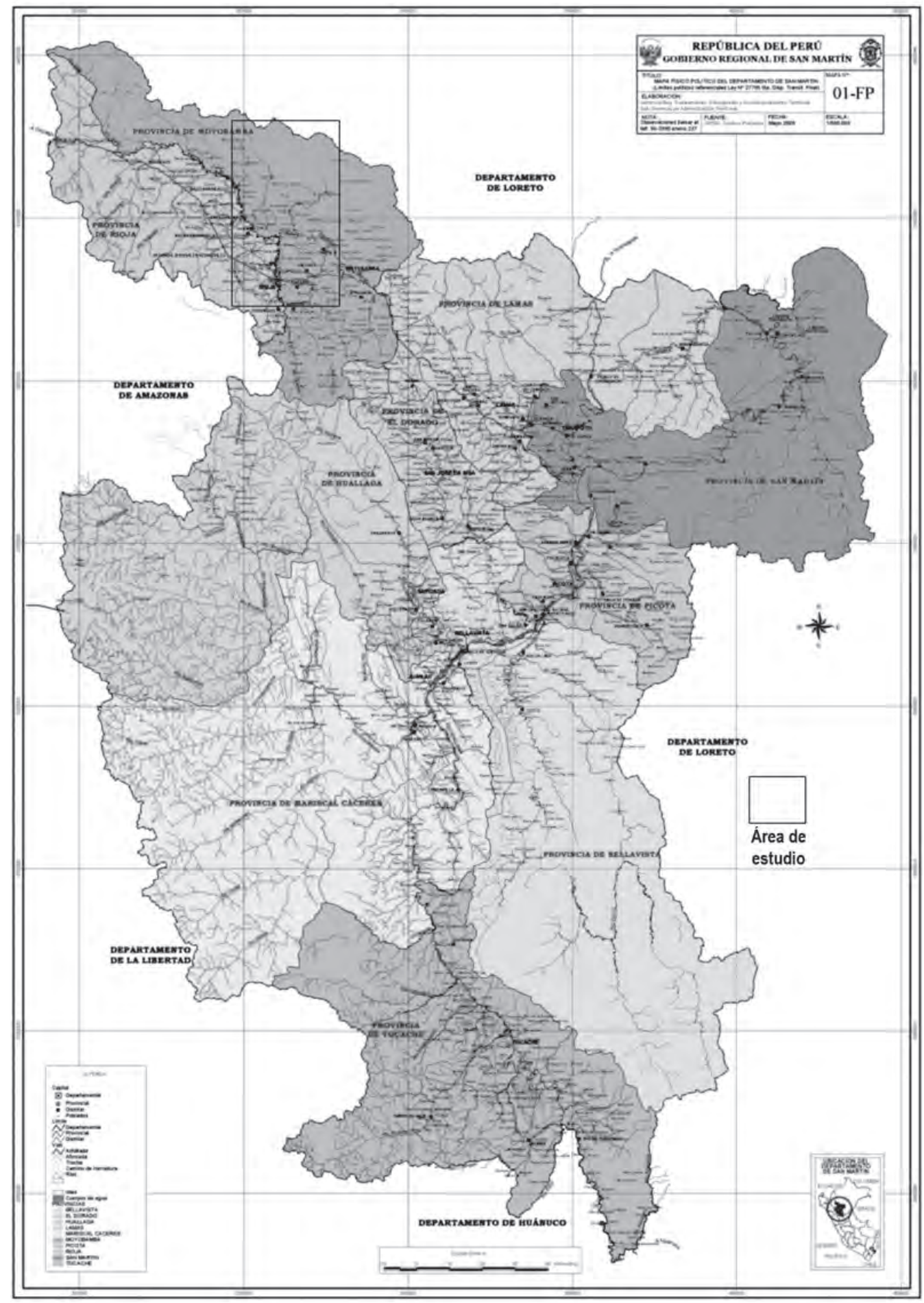

Figura 2. Plano del departamento de San Martín, con la ubicación del área de estudio. 


\section{Sitios arqueológicos de la cuenca medio-Alto del Río Mayo}

Como resultado del proceso de investigación realizado en la localidad de Moyobamba, ha sido posible identificar un total de 25 sitios arqueológicos, los cuales pertenecen mayoritariamente a periodos Tardíos. Sin mbargo ha sido posible identificar algunos sitios que corresponderían a periodos más tempranos.

\section{A. SITIOS TEMPRANOS}

Existen un conjunto de sitios arqueológicos, que por sus características, diferentes al patrón tardío conocido, planteamos como hipótesis de trabajo, que corresponderían a periodos tempranos. Esto deberá ser definido en futuros trabajos de investigación con excavaciones.

Entre los sitios identificados que por sus características pertenecerían a periodos tempranos figura el sitio de Rumiyacu (My-024), que se ubica en la localidad de Moyobamba, en la margen izquierda del río Rumiyacu, en una zona donde una amplia quebrada se une a esta por la misma margen. El punto datum del sitio se ubica en las coordenadas UTM¹: $0281561 \mathrm{E}, 9328442 \mathrm{~N}$, y a $966 \mathrm{msnm}$. El asentamiento se encuentra emplazado sobre un sobre un montículo natural, de $10 \mathrm{~m}$ de altura, con muros de contención, conformado por rocas de gran tamaño, que se eleva en terreno casi plano. Se aprecia en la cima rocas grandes que delimitan espacios de planta irregular. No se ha podido identificar material cerámico debido a la vegetación herbácea existente en la superficie, pero sí batanes de regular tamaño. Por las características del sitio y su similitud con otros de la provincia de San Martín, como es el caso de Ushpapangal (Ravines 1995: 15-24), el sitio correspondería al Periodo Formativo. Se observa solo un 10\% de las estructuras debido al mal estado de conservación, y por la vegetación herbácea existente en la superficie de las estructuras. Muchas estructuras están colapsadas. Parte del sitio está siendo urbanizado.

Otro sitio de aparente ocupación temprana es Sarahuasi (My-002), que se ubica en la localidad de Marona, en la margen izquierda de la quebrada Sarahuasi (margen derecha del río Mayo), junto a su cauce mismo, a unos $300 \mathrm{~m}$ de distancia de la carretera Belaunde Terry y a $500 \mathrm{~m}$ antes que esta quebrada desemboque al río Mayo por su margen derecha. El punto datum se ubica en las coordenadas UTM: 0289916 E, $9327899 \mathrm{~N}$, y a $860 \mathrm{msnm}$. El sitio se expande sobre una ladera natural de pendiente media que emerge desde el cauce mismo de la quebrada Sarahuasi. Está conformado por una estructura piramidal, con una estructura circular baja. Esta estructura sería tardía y tiene 11,70 m de diámetro y está delimitado por piedras de tamaño grande y mediano, observándose solo una hilada, debido al desplome que han sufrido. Algunas piedras de gran tamaño llegan a tener hasta 0,60 m de altura. Inmediatamente hacia el lado sur y cercando esta estructura por ese lado, se eleva un montículo, que ha sido edificado aprovechando un promontorio natural. Este montículo ha sido adecuado mediante aterrazamientos y muros de contención consecutivos de piedras canteadas unidas con argamasa simple. El montículo presenta hasta cinco niveles de aterrazamientos y $10 \mathrm{~m}$ de altitud con respecto a la superficie del recinto. Los muros de contención presentan piedras canteadas de tamaño regular y pequeño con medidas promedio de 0,20 m, unidas con argamasa simple, la cual por acción de la humedad del clima y la lluvia se ha desarticulado. En la parte superior se aprecia un camino prehispánico hacia el lado posterior, que discurre de oeste a este. Por encima de estas estructuras se emplazan hasta seis niveles de aterrazamientos consecutivos, de 0,35 $\mathrm{m}$ de altitud como promedio. Los muros se muestran muy erosionados, producto del derrumbe y la acción intrusita de las raíces. No se ha podido identificar cerámica debido a la vegetación herbácea existente en la superficie. El sitio dataría del Horizonte Temprano y se encuentra en mal estado de conservación. El sitio ha sido muy erosionado debido a factores climáticos y antrópicos. Los muros han colapsado, solo se conservan en pie aquellos que están cubiertos fijamente por la vegetación herbácea (muros de contención del montículo), pero

1 Todos los puntos UTM están en Sistema WGS-84 y corresponden a la zona 18. 
la impregnación intrusiva de las raíces han hecho que se pierda el mortero, mientras que algunas piedras se han desplomado. La fuerte humedad y las lluvias torrenciales han erosionado y ocasionado el desplome de muros. Se desarrolla la actividad agropecuaria en el terreno.

\section{B. SITIOS ARQUEOLÓGICOS TARDÍOS}

Se identificó otros 23 sitios arqueológicos correspondientes a periodos tardíos. Estos sitios han sido clasificados según la funcionalidad en los siguientes tipos:

\section{a. Conjuntos arqueológicos con estructuras públicas}

En base al reconocimiento realizado en el área referida ha sido posible identificar un asentamiento de grandes dimensiones, con diferenciación de sectores y estructuras públicas asociadas, el cual con una datación tardía (Intermedio Tardío y Horizonte Tardío), se habría constituido en el poblado de mayor importancia de la zona, sede del poder político al momento de la llegada de los españoles a la región.

Mayumarca (My-006). Es el asentamiento de mayores dimensiones y de mayor complejidad espacial en la zona de estudio. Se ubica frente al pueblo de Marona, en la margen derecha del río Mayo, a $500 \mathrm{~m}$ de la carretera Belaunde Terry, sobre la ladera de una amplia terraza aluvial. El punto datum del sitio se ubica en las coordenadas UTM: 0287519 E, 9328271 N, y a 857 msnm. El sitio está despejado de vegetación arbórea, resaltando pastizales en los alrededores. Hacia el lado occidental el sitio limita con una quebrada de cauce reducido. El sitio está conformado por un conjunto de estructuras arquitectónicas, formando recintos y muros de gran longitud, definiendo áreas públicas. Las estructuras se asientan sobre una gran área, aglutinadas en tres sectores: Sector A. Se localiza al noroeste del sitio, en este sector se encuentra la mayor cantidad de estructuras (aproximadamente 25), conformando recintos de forma ovalada con medidas de 6 a 12 m de diámetro, aglutinados y adosados entre sí. Hacia el lado norte de este sector existe un muro aislado de orientación norte-sur, de $130 \mathrm{~m}$ de largo. No existe ninguna planificación del uso del espacio en la construcción de los recintos. Sector B. Conformado por un conjunto de estructuras arquitectónicas (20 aproximadamente), ubicadas en el lado sur del sitio, delimitados por un muro con orientación noreste-sureste de $35 \mathrm{~m}$ de largo. Los recintos son ovalados con un diámetro de 5 a 9 $\mathrm{m}$. Sector C. Ubicado al lado oriental del sitio, conformado por cinco recintos ovalados, aglutinados y adosados entre sí, con diámetro de similares dimensiones al sector anterior.

En la parte central del sitio se localiza una estructura aislada de forma cuadrangular con esquinas curvas de 15 x 6 m de dimensiones. No se ha podido identificar en todo el sitio dispersión de cerámica, debido a la vegetación herbácea existente en la superficie. El sitio data del Intermedio Tardío, según la morfología de los recintos. El sitio se encuentra en mal estado de conservación, solo se conserva un $30 \%$ de las estructuras, esto a consecuencia del colapso de los muros. Se aprecia asimismo en la parte baja, grandes corrales de forma cuadrangular (de más de $50 \mathrm{~m}$ por lado) y rectangular, pero con esquinas curvas, y con recintos ovalados en las esquinas internas. Este tipo de edificación sería repetitivo en la región, por lo que constituiría un patrón.

\section{b. Sitios ceremoniales}

Asimismo se ha podido identificar un asentamiento, dada su configuración espacial, de aparente función ceremonial. Este sitio denominado El Templo (My-012) se encuentra ubicado en la margen izquierda de una pequeña quebrada, cuyas aguas discurren por el centro poblado de Marona, hasta vertirse al río Mayo por su margen derecha. Hacia el lado norte a una distancia de $200 \mathrm{~m}$ se localiza el sitio de Marona Huayco. El punto datum del sitio se ubica en las coordenadas UTM: 288219 E, 9327721 $\mathrm{N}$, y a $857 \mathrm{msnm}$. El asentamiento se encuentra emplazado sobre un área de pendiente media, cuya superficie está cubierta de pastizales. El sitio está conformado por una estructura de forma cuadran- 
gular con esquinas curvas, de $11 \mathrm{~m}$ de diámetro, construido sobre un pequeño aterrazamiento, notándose la alineación de piedras canteadas en el lado norte del recinto, solo hasta la mitad del mismo, con medidas entre 0,30 y 0,55 m. En la parte central y externa del muro de la estructura, se definió un ducto de ventilación subterráneo que recorre hasta la parte central del recinto, en la cual se nota una fosa de forma ovalada sin ningún material constructivo, de 2,60 m de longitud y de 0,55 $\mathrm{m}$ de profundidad. El sistema constructivo del ducto es en base a piedras labradas, las cuales presentan desgaste artificial de forma plana, no presentando argamasa entre las uniones. El ducto de ventilación tiene una longitud de 3,50 $\mathrm{m}$ y su abertura tiene una medida horizontal de 0,30 $\mathrm{m}$ y de vertical de 0,35 $\mathrm{m}$. Sobre el lado superior de la abertura existe una piedra labrada de forma rectangular de 0,40 $\mathrm{m}$ horizontalmente y de 0,10 m verticalmente. Hacia el lado noreste del recinto, a una distancia de 7,30 m, se localiza una estructura pequeña de forma ovalada, con medidas de 1,90 x 1,60 m construido en base a piedras canteadas medianas de una longitud entre 0,40 y 0,55 m, se nota 12 piedras que forman la estructura en su superficie. Las estructuras presentan piedras canteadas de tamaño regular y pequeñas con medidas promedio de 0,30 a $0,55 \mathrm{~m}$ de longitud. No se ha podido identificar material cultural alguno, debido a la vegetación herbácea existente en la superficie. El sitio data del Intermedio Tardío. Se observa solo un $15 \%$ de las estructuras debido al mal estado de conservación, por el colapso de los muros. Se nota que parte de los muros han colapsado, debido a factores climáticos y al desarrollo de actividades agropecuaria desarrolladas en la actualidad, pues al momento del registro, alrededor del sitio pastaban ganado vacuno.

El centro ceremonial de mayor importancia en la zona era el Morro de la Calzada, la cual habría sido considerada como especie de paqarina de los pueblos que ocuparon este territorio. Pues por su ubicación, emergiendo en el medio del valle, por su unidad geológica, no asociada a otras estribaciones, y por su considerable altitud, fue objeto de culto y adoración. Es por ello que el antiguo poblador Moyobambino lo consideró un área ceremonial sagrada, edificando santuarios en su cima y áreas funerarias en sus laderas bajas y medias.

\section{c. Sitios domésticos}

Existen por su parte 10 sitios arqueológicos de función doméstica, los cuales, aunque se concentran mayormente en la localidad de Marona, se hallan también en los otros sectores recorridos como Quilloalpa y Condorpampa.

Marona (My-004). Se ubica en la localidad del mismo nombre, en la margen derecha del río Mayo, a unos $250 \mathrm{~m}$ de distancia de la carretera Belaunde Terry, a $200 \mathrm{~m}$ después de pasar el centro poblado de Marona. El punto datum se ubica en las coordenadas UTM: 0289077 E, 9328417 N, y a 885 msnm. El sitio arqueológico se encuentra ubicado en medio de una amplia terraza aluvial, en la parte media del cerro Marona, terraza conformada por depósitos arcillosos (a $100 \mathrm{~m}$ por encima del sitio Ginapata). El cerro Marona está ubicado por encima del extremo oriental del actual centro poblado de Marona, en la margen izquierda del río Mayo. El terreno está cubierto de vegetación herbácea y poncianas. El sitio está conformado por un conjunto de aproximadamente 20 estructuras definidas por alineamientos de piedras canteadas medianas y grandes, que conforman espacios rectangulares amplios de 4 a $6 \mathrm{~m}$ de largo en promedio, así como otras estructuras ovaladas, semiovaladas e irregulares. Los muros están muy destruidos, observándose apenas tres hileras superpuestas de piedras canteadas medianas, con argamasa simple (muy deteriorado). No se ha podido identificar material cultural asociado debido a la vegetación herbácea existente en la superficie. El sitio de Marona data del Intermedio Tardío y Horizonte Tardío y se habría constituido en uno de los asentamientos más amplios de esta zona, junto con Mayumarca. El sitio se encuentra en pésimo estado, todas las edificaciones han colapsado, principalmente por factores antrópicos y naturales. Los muros han colapsados, debido a factores climáticos y al desarrollo de actividades agropecuarias desarrolladas en la actualidad. 
El Palto (My-005). Se ubica en la localidad de Marona, en la margen derecha del río Mayo, a unos 1000 $m$ de distancia de la carretera Belaunde Terry, frente al centro poblado de Marona. El punto datum se ubica en las coordenadas UTM: 0286700 E, 9328360 N, y a 905 msnm. El sitio se encuentra ubicado en medio del espolón natural plano del cerro Marona, ubicado al lado suroeste del actual centro poblado de Marona, en la margen derecha del río Mayo. El sitio está conformado por dos estructuras representativas, una corresponde a un gran recinto de forma trapezoidal cuyo eje mayor presenta una orientación noroeste-sureste y el muro de mayor extensión presenta una longitud de $90 \mathrm{~m}$ de largo. En el eje menor de orientación noreste-suroeste los muros presentan una longitud de $65 \mathrm{~m}$. A cinco metros de la esquina norte externa de la estructura se asocia un muro con orientación hacia el noroeste, con una longitud de $42 \mathrm{~m}$, sin encerrar ningún espacio definido. La otra estructura corresponde a un recinto de forma ovalada ubicado en la esquina oeste interna, de $10 \mathrm{~m}$ de diámetro. No es posible reconocer la totalidad de los muros, solo se observa en la superficie el alineamiento de piedras que conforman los muros de las dos estructuras. En algunos tramos del recinto trapezoidal se nota la construcción del muro en forma de pircado, no definiéndose la presencia de argamasa en el paramento del muro. Se aprecia además numerosos recintos de planta ovalada dispersos por el terreno y aislados. No se ha podido identificar materiales asociados, debido a la vegetación herbácea existente en la superficie. El sitio de El Palto data del Intermedio Tardío. Se observa solo un 10\% de las estructuras debido al mal estado de conservación, por el colapso de los muros.

El Pedregal (My-008). Se ubica en la localidad de Marona, en la margen derecha del río Mayo, a unos $100 \mathrm{~m}$ de distancia de la carretera Belaunde Terry. El punto datum se ubica en las coordenadas UTM: 289589 E, 9328254 N, y a 885 msnm. El sitio se emplaza sobre la cumbre de una pequeña lomada de poca elevación que se emerge desde la carretera misma. Hacia la parte media de las estribaciones laterales al valle que se elevan a poca distancia del río, y que conforman la cadena de cerros localizados al sur del Centro Poblado de Marona. A pesar de la destrucción que ha sufrido el sitio se puede observar todavía terrazas ovaladas y algunos recintos circulares construidos en base a piedras canteadas, asentados en las partes planas del área. Cabe resaltar un camino que recorre por el medio del sitio con orientación este-oeste, el cual tiene un ancho de $2 \mathrm{~m}$, moderno ya que recorre el mismo sentido de las torres eléctricas y una de ellas está sobre el mismo sitio arqueológico; por lo que el camino había sido construido para llevar los materiales en la construcción de las mismas. No se ha podido identificar materiales culturales asociados debido a la vegetación herbácea existente en la superficie. El sitio pertenecería al Intermedio Tardío, según la morfología de las terrazas. El estado de las estructuras es deplorable, ya que solo se definen algunas alineaciones de piedras canteadas y que en cierta manera nos indican las estructuras que conformaban.

Marona Huayco (My-009). Se ubica en la localidad de Marona, en la margen derecha del río Mayo, en medio del cauce de la quebrada de Marona y en las pequeñas terrazas laterales. El punto datum se ubica en las coordenadas UTM: 0288043 E, 9327998 N, y a 855 msnm. En la margen izquierda del cauce de la quebrada se observan dos aterrazamientos. El superior ubicado en una suave pendiente de la quebrada, de forma ovalada con un diámetro de $15 \mathrm{~m}$ aproximadamente, con el muro de contención de 0,75 $\mathrm{m}$ de altura. Tiene un sistema constructivo a base de piedras de tamaño mediano de hasta 0,40 m de diámetro. La terraza inferior está mejor conservado y es también de forma ovalada, con un diámetro de $25 \mathrm{~m}$ y una altura de 0,85 m; presenta piedras canteadas de tamaño regular de hasta 0,60 $\mathrm{m}$ de largo. En la margen derecha de la quebrada hacia el noroeste se observa algunos recintos de forma ovalada, delimitado por una sola hilada de piedras, uno de ellos tiene 4,50 m de diámetro. No se ha podido identificar material cerámico debido a la vegetación herbácea existente en la superficie. El sitio pertenece al Intermedio tardío. Este sitio estaría asociado con el sitio de Marona. Se observa solo un $15 \%$ de las estructuras debido al mal estado de conservación. 
del sitio es de forma ondulada, cubierta de pastizales. Hacia el lado suroeste a una distancia de 250 $\mathrm{m}$ se localiza el sitio de Marona Huayco. El punto datum se ubica en las coordenadas UTM: 288118 E, $9328247 \mathrm{~N}$, y a $859 \mathrm{msnm}$. El asentamiento se encuentra emplazado sobre un área de superficie plana, cuyo suelo está cubierto de pastizales. El sitio arqueológico está conformado por un conjunto de recintos de forma circular y cuadrangular, construidos en base a piedras canteadas, presentando un diámetro de 6 a $8 \mathrm{~m}$. En el medio de las estructuras se observa un desnivel de la superficie, de forma alargada y que presenta una orientación de norte a sur, de hasta $2 \mathrm{~m}$ de profundidad, que podría tratarse de un patio común de los recintos. Por el lado oeste del desnivel se observa las bases de un muro de $20 \mathrm{~m}$ de longitud de orientación noreste-suroeste, para después doblar hacia el sureste, en una longitud de $22 \mathrm{~m}$; es decir en planta presenta la forma de una «L». En el lado este del sitio también existen las bases de otro muro con una longitud de $40 \mathrm{~m}$ aproximadamente, asociado a recintos hacia ambos lados del mismo. No se ha podido identificar material cultural alguno debido a la vegetación herbácea existente en la superficie. El sitio dataría del Periodo Intermedio Tardío y del Horizonte Tardío, se infiere la periodificación, según la morfología de los recintos asociados, así como por la asociación con el sitio de Marona.

Juninguillo (My-017). Se ubica políticamente en la localidad de Juninguillo, en la margen izquierda del río Mayo, sobre un terreno de poca pendiente, a $10 \mathrm{~m}$ de distancia del río Mayo. Está cubierto totalmente por pasto natural. El punto datum se ubica en las coordenadas UTM: 0289150 E, 9330070 N, y a $856 \mathrm{msnm}$. El asentamiento se encuentra emplazado junto al cauce mismo del río Mayo. El acceso al sitio se realiza por un camino de herradura proveniente el caserío de Marona, en la otra margen, cruzando el río por una balsa, siguiendo por un camino de herradura a una distancia de $1000 \mathrm{~m}$ aprox. El sitio está conformado por un conjunto de recintos de forma ovalada, de entre 2 y $3 \mathrm{~m}$ de diámetro, emplazados sobre el terreno natural arcilloso. Solo es posible observar las bases de los recintos, de $0,10 \mathrm{~m}$ de altura. También se aprecian dos alineamientos de piedras, el primero de $3 \mathrm{~m}$ de largo y el segundo de $2 \mathrm{~m}$, ambos orientados en dirección al río Mayo y ambos dispuestos de forma convergente con respecto al río. Las piedras que conforman los muros son de entre 0,30 y 0,45 m de largo y 0,30 m de ancho, habiéndose obtenido en las inmediaciones. No se identificó material cultural asociado. Por las características de las estructuras se trataría de un asentamiento del Intermedio Tardío. El sitio se encuentra en un mal estado de conservación. El sitio ha sido muy erosionado por factores climáticos, como por las fuertes lluvias que azotan la región, así como la inundación o desborde del río Mayo en épocas de crecida.

Quilloallpa (My-020). Se ubica políticamente en la localidad de Quilloallpa, en la margen izquierda del río Yanayacu, cuyas aguas discurren por los territorios de los Centros Poblados de Quilloallpa y Sugllaquiro. El área arqueológica está localizada al noroeste del Centro Poblado de Quilloallpa, sobre un terreno de pendiente media, cuya superficie está cubierto de pastizales y pequeños arbustos. El punto datum se ubica en las coordenadas UTM: 0284098 E, 9344964 N, y a 1043 msnm. El sitio arqueológico está conformado por un aterrazamiento, orientado en dirección este-oeste, construido a base de piedras canteadas. Tiene $4,10 \mathrm{~m}$ de longitud. En cada extremo del mismo se ubican dos estructuras ovaladas con medidas de 2,40 y 1,40 m de diámetro, con muros de 0,55 a 0,40 $\mathrm{m}$ de ancho. En el lado norte del área se aprecia dos alineamientos de piedras, al parecer serian parte de una estructura habitacional. La primera con medidas de $9 \mathrm{~m}$ de largo, mientras la segunda presenta medidas de 6,50 $\mathrm{m}$ de longitud y 0,40 $\mathrm{m}$ de ancho aproximadamente. Además en el lado suroeste se observa parte de un muro, construido en base a piedras canteadas sin presencia de argamasa con medidas de 2,50 $\mathrm{m}$ de longitud, 0,45 $\mathrm{m}$ de ancho y una altura de 0,75 $\mathrm{m}$. Las estructuras presentan piedras canteadas de tamaño regular y pequeñas con medidas promedio de 0,55 a 0,35 m de longitud. No se ha podido identificar material cultural asociado, debido a la vegetación herbácea existente en la superficie. El sitio corresponde al Intermedio tardío. El sitio se encuentra en un regular estado de conservación. 
Quilloallpa Pata (My-022). Se ubica en la localidad de Quilloallpa, en la margen derecha de la carretera que se dirige hacia el centro poblado de Quilloallpa. Se halla en una pequeña pendiente con dirección al norte, cuya superficie está cubierta de pastizales, pequeños arbustos y matas de pacae. Además se puede notar límites boscosos a los alrededores del área arqueológica. El punto datum se ubica en las coordenadas UTM: 0283946 E, 9344011 N, y a 1177 msnm. El sitio arqueológico está conformado por un conjunto de estructuras cuadrangulares, edificadas sobre un espacio plano y de pendiente media, notándose en la parte superior del área, un alineamiento de piedras canteadas y/o amorfas de tamaños variados orientados en dirección este-oeste, con una longitud de $8 \mathrm{~m}$. Al parecer fue parte de un aterrazamiento. Además en dirección sur-norte se aprecia alineamientos de grandes bloques de piedras con una longitud de $6 \mathrm{~m}$. Estos bloques oscilan en una dimensión de 1 a 1,20 m de longitud y de 0,90 a $1 \mathrm{~m}$ de ancho. Por otro lado en la parte inferior derecha del área arqueológica se definió una estructura ovalada no muy definida elaborada a base de piedras canteadas la cual presenta un diámetro de 4,50 m. No se ha podido identificar otros materiales culturales en superficie debido a la vegetación herbácea existente. El sitio corresponde al Intermedio Tardío. Se observa solo un 10\% de las estructuras debido al mal estado de conservación, por el colapso de los muros, así mismo por la vegetación impregnada en la superficie de las estructuras. Se nota que parte de los muros han colapsados, debido a factores climáticos y al desarrollo de actividades agropecuaria desarrolladas en la actualidad, pues al momento del registro alrededor del sitio pastaban ganado vacuno. El sitio arqueológico está cubierto de vegetación herbácea impregnada en las estructuras. El sitio ha sido muy erosionado debido a factores climáticos y antrópicos.

Condorpampa (My-023). Se ubica en la localidad de El Condor, ubicado en la margen derecha del río Yanayacu a pocos metros de dicha localidad. El terreno es de pendiente media, cuya superficie está cubierta de vegetación herbácea (pastizales y pequeños arbustos). El punto datum se ubica en las coordenadas UTM: $0287800 \mathrm{E}, 9345548 \mathrm{~N}$, y a $992 \mathrm{msnm}$. El sitio arqueológico está conformado por un conjunto de estructuras, sobre un espacio plano y de pendiente media, notándose un aterrazamiento construido en base a cantos rodados de forma irregular y de tamaños variados, con medidas de 0,40 a 0,15 m, y una longitud de $8 \mathrm{~m}$. Además en dirección sureste se aprecian tres aglomeraciones de piedras con tamaños medianos y pequeños las cuales presentan un diámetro que oscilan entre 4 a 3 $\mathrm{m}$ respectivamente. No se ha podido identificar materiales asociados debido a la vegetación herbácea existente en la superficie. El sitio corresponde al Intermedio Tardío.

Bombonajal (My-001). Está ubicado en la localidad de Gera, en la margen izquierda del río Gera, afluente del río Mayo (por su margen derecha), sobre una pequeña terraza aluvial, junto al cauce mismo del río (a 3,50 m de altitud con respecto al cauce). Está cubierto totalmente por pasto natural, y junto a un conglomerado vegetativo, que se constituye en el monte ribereño natural. El punto datum del sitio se ubica en las coordenadas UTM: $0291992 \mathrm{E}, 9325264 \mathrm{~N}$, y a 818 metros sobre el nivel del mar. El sitio está conformado por un conjunto de recintos de forma rectilineal con esquinas ovaladas, edificadas sobre pequeños aterrazamientos. La disposición de los recintos es aglutinada hacia el lado norte, no notándose claramente la disposición por el mal estado de conservación y por estar cubierto de una densa vegetación herbácea. Una de las estructuras mejor conservadas, presenta solo un alineamiento de piedras canteadas medianas y pequeñas, de una hilera de altura (de 0,40 a 0,45 $\mathrm{m}$ ), con medidas de $4 \mathrm{~m}$ de largo aproximadamente (en su eje este-oeste). Hacia la parte baja del sitio, cerca de su cauce se observan los muros de contención en largas hileras que se orientan en un eje este-oeste. Hacia el lado sur del sitio se aprecia un amplio espacio irregular que contiene en la parte central una piedra natural aflorante en posición vertical, que domina el entorno a modo de Huanca. El sitio tiene un área de $28844 \mathrm{~m}^{2}$ (según la propuesta de delimitación). Los materiales constructivos identificados son piedras canteadas de tamaño regular y pequeñas de 0,33 a 0,30 m aproximadamente, no identificándose mortero alguno por el mal estado de conservación. Se encontró en la parte baja del sitio, en un área erosionada, algunos fragmentos de cerámica muy erosionados, de pasta mediana 
y pocos temperantes (arena). Por otra parte, en el extremo sur del sitio se halló un fragmento diagnóstico, correspondiente a un borde evertido, con una pasta de $7 \mathrm{~mm}$ de grosor, cocción reductora, y acabado de superficie alisado; que dataría por su morfología al periodo Horizonte Tardío. Por las características de la estructura se trataría de un asentamiento del Intermedio Tardío (posiblemente un sitio Chachapoyas rural), con datación hasta el Horizonte Tardío (según el fragmento evertido identificado). El sitio se encuentra en un mal estado de conservación. Se observa solo un 10\% de las estructuras por el mal estado de conservación del sitio, pero solo las bases de las mismas por el colapso de los paramentos.

\section{d. Paisajes cultural arqueológico}

Ginapata (My-003). Se ubica en la localidad de Marona, en la margen derecha del río Mayo, a unos $150 \mathrm{~m}$ de distancia de la carretera Belaunde Terry a $100 \mathrm{~m}$ después de pasar el centro poblado de Marona. El punto datum se ubica en las coordenadas UTM: 0289015 E, 9328655 N, y a 860 msnm. El sitio se expande en medio del espolón natural del cerro Marona, ubicado por encima del extremo oriental del actual centro poblado de Marona, en la margen derecha del río Mayo. El terreno es de pendiente media. El acceso al sitio se realiza por un camino de herradura proveniente desde el kilómetro 501,5 de la carretera Fernando Belaunde Terry, pasando por el centro poblado de Marona, donde se toma un camino de herradura hacia la derecha hasta el sitio arqueológico. El sitio arqueológico está conformado por un conjunto de terrazas. Solo se observa la disposición de dos alineamientos consecutivos y escalonados de piedras, debido al mal estado de conservación, a los desplomes de los muros, así como por estar cubierto de una densa vegetación. Estos alineamientos se constituyen en los muros de contención de las terrazas. El superior está mejor conservado, presenta piedras canteadas de tamaño mediano, y tiene $75 \mathrm{~m}$ de largo, con una terraza de 0,58 $\mathrm{m}$ de alto y $0,45 \mathrm{~m}$ de ancho. El muro de contención de la estructura agrícola inferior está en peor estado y tiene 0,30 $\mathrm{m}$ de ancho, $25 \mathrm{~m}$ de largo y 0,58 $\mathrm{m}$ de altura, mientras que la terraza tiene $5 \mathrm{~m}$ de ancho. Los muros de contención presentan piedras canteadas de tamaño regular y pequeñas con medidas promedio de 0,28 a 0,32 m aproximadamente. Las dos estructuras están paralelas y discurren en una orientación este-oeste, adecuándose a la ladera de pendiente media del terreno. Hacia la parte superior de las estructuras (lado oeste) se aprecia un recinto de forma ovalada, de 0,45 $\mathrm{m}$ de diámetro, delimitado por una sola hilada de piedras medianas, y de mal estado de conservación. No se ha podido identificar materiales culturales en superficie debido a la vegetación herbácea existente en la superficie. El sitio dataría del Intermedio Tardío y del Horizonte Tardío. Se infiere la periodificación, según la morfología del recinto asociado, así como por la asociación con el sitio de Marona. El sitio se encuentra en un mal estado de conservación. Se observa solo un 15\% de las estructuras debido al mal estado de conservación, por el colapso de los muros.

Muralla de Marona (My-007). Se ubica en la localidad de Marona, en la margen derecha del río Mayo, a unos $500 \mathrm{~m}$ de distancia de la carretera Belaunde Terry, frente al centro poblado de Marona. El punto datum se ubica en las coordenadas UTM: 2900015 E, $9327120 \mathrm{~N}$, y a 1023 msnm. El sitio se ubica sobre la cumbre media de las estribaciones laterales al valle que se elevan a poca distancia del río, y que conforman la cadena de cerros localizados al sur del centro poblado de Marona. El sitio está conformado por una muralla de $230 \mathrm{~m}$ de longitud, construida de piedras canteadas medianas entre 20 a $40 \mathrm{~cm}$ de longitud. La muralla no es recta, sino de forma ondulada, y solamente se conserva la parte del basamento. Por su ubicación localizada sobre una de las cumbres laterales del cerro, podría cumplir la función de demarcación territorial. A ambos extremos de la muralla se ubican quebradas que encerraban la estructura. No se ha podido identificar material cultural en superficie debido a la vegetación herbácea existente en la superficie, así como tampoco ha sido posible definir la filiación cultural. La muralla se encuentra en mal estado de conservación. Solo se conserva la alineación de las piedras del basamento de la muralla, en gran parte de su longitud. 


\section{e. Sitios con dispersión de cerámica}

San Lorenzo (My-010). Se ubica en el sector de San Lorenzo, en la margen derecha del río Mayo, en medio del valle mismo. El punto datum se ubica en las coordenadas UTM: 0285172 E, 9330874 N, y a $843 \mathrm{msnm}$. El sitio se localiza en medio del valle mismo, en un terreno plano, junto a la carretera Belaunde Terry. No se ha definido la funcionalidad del sitio, pues solo se halló fragmentos de cerámica dispersos en el terreno, tanto diagnósticos (conformado por bordes y cuerpos decorados), así como material cerámico no diagnóstico (cuerpos sin decoración). Los fragmentos diagnósticos identificados, están conformados por bordes evertidos, invertido convexo; cuerpos decorados con decoración incisa lineal y pintados en colores rojo violáceo y crema; de textura media, con un grosor variable de 0,6 a 0,8 cm. En cuanto a la cocción, algunos presentan cocción oxidante y otras cocción reductora. También se identificó cuerpos llanos sin decoración (no diagnósticos). El sitio se encuentra en mal estado de conservación ya que solo se hace posible la visibilidad de los fragmentos de cerámica en la parte con escasa vegetación herbácea.

San José del Morro (My-011). Se ubica en el sector de San José del Morro, en la margen derecha del río Mayo, en medio del valle mismo, en un terreno plano. El punto datum se ubica en las coordenadas UTM: 0276738 E, $9330407 \mathrm{~N}$, y a $888 \mathrm{msnm}$. El sitio se localiza en medio del valle mismo, en un terreno plano, cerca de la carretera Belaunde Terry. No se ha definido la funcionalidad del sitio. En el sitio se encontró material cultural cerámico disperso y sin contexto definido. Se trata de diez fragmentos asociados pertenecientes a una sola vasija abierta, correspondiente a una olla, con borde ligeramente evertido, cuello estrecho, paredes convergentes y base redonda. Esta vasija presenta entre el borde y el cuerpo un acabado de digitado en alto relieve y en su superficie externa e interna (borde) se observa restos de hollín. Los fragmentos presentan: cocción: reductora, grosor 8 mm y textura media. Solo se identificó los fragmentos de cerámica. El sitio pertenece al Intermedio Tardío. El sitio se encuentra en mal estado de conservación, utilizado para el pastoreo.

La Esperanza (My-014). Se encuentra sobre una superficie plana, en la margen derecha de la quebrada San Luis, se expande sobre un terreno de superficie horizontal la cual se encuentra rodeada de vegetación herbácea, pastizales y arrozales; la misma que hace difícil la visión del material cultural (cerámica). El punto datum se ubica en las coordenadas UTM: 258214 E, 9349218 N y a 824 msnm. Se encontró material cultural cerámico disperso. Se trata de fragmentos no diagnósticos (cuerpos sin decoración). Los fragmentos presentan: cocción: reductora, textura: media, con un grosor: variable de 5 a 6 aproximadamente. El sitio se encuentra en mal estado de conservación ya que el terreno donde se localiza el material cerámico se encuentra cubierto fijamente de vegetación herbácea (pastizales) y arrozales.

El Limón (My-015). Se encuentra en la localidad de Valle de La Conquista, en la margen izquierda del río Mayo, sobre una superficie plana, cubierta de vegetación herbácea, pastizales, arrozales. El punto datum se ubica en las coordenadas UTM:0261078 E, $9349218 \mathrm{~N}$ y a $823 \mathrm{msnm}$. Se encontraron fragmentos de cerámica tanto diagnóstico (bordes y cuerpos decorados), así como material cerámico no diagnóstico (cuerpos sin decoración), dispersos en el terreno. El grosor de la pasta es variable. Un borde indica que la vasija tiene un diámetro de $22 \mathrm{~cm}$, la pasta mediana, con un grosor de 0,8 a $1 \mathrm{~cm}$, textura media, cocción reductora. El sitio corresponde al Periodo Intermedio Tardío y se encuentra en mal estado de conservación ya que solo se hace posible la visibilidad de los fragmentos de cerámica en la parte con escasa vegetación herbácea.

Perla de Indañe (My-016). Se encuentra ubicado en la margen derecha de una pequeña quebrada y cubierto totalmente de sembríos de café, en la margen derecha del río Mayo. La superficie donde se asienta el sitio es relativamente inclinada hacia el noroeste. El punto datum se ubica en las coordenadas UTM: 0277243E, 9328452 N, y a 895 msnm. El sitio está conformado por una superficie disturbada, debido a los sembríos existentes, pero después de una limpieza de las hojas se pudo 
definir dispersión de cerámica en el sitio, de los cuales los más representativos corresponden a fragmentos diagnósticos. Un fragmento corresponde a la parte del borde de una vasija cerrada con engobe crema externo, el borde presenta reforzamiento externo, con una ligera prolongación hacia la parte media de la vasija, además presenta una delgada franja en alto relieve con pequeñas incisiones verticales. Otro fragmento es de una vasija cerrada con borde reforzado externo y labio plano, la parte del cuello está elaborado con la técnica de enrollamiento, presenta en la parte inferior del tiesto decoración en base a incisiones diagonales. Otro fragmento es la parte del cuerpo de una vasija con decoración incisa diagonal. Por referencia del propietario del predio se tuvo conocimiento de una hacha de piedra en forma de $\mathrm{T}$, de $5 \mathrm{~cm}$ de ancho y de $4,3 \mathrm{~cm}$ de alto y de punta biselada, el cual lo recolectó de una zona aledaña al sitio y se registró como material de referencia. El sitio data del Intermedio Tardío.

Huascayacu (My-018). Se ubica en la localidad de Buenos Aires, en la margen izquierda del río Huascayacu, afluente a su vez del río Mayo por su margen izquierda, sobre un terreno de poca pendiente. Está cubierto por cultivos de frijol de palo y cafetales. El punto datum se ubica en las coordenadas UTM: $0268415 \mathrm{E}, 9346496 \mathrm{~N}$, y a $853 \mathrm{msnm}$. El asentamiento se encuentra emplazado sobre un terreno de mediana gradiente. El sitio está conformado por dispersión de cerámica sin decoración, por la superficie. Se identificó material cerámico, de los cuales sobresalen tres fragmentos diagnósticos. Uno de ellos es un borde de cocción oxidante, de forma abierta, borde evertido y reforzamiento externo, de $6 \mathrm{~mm}$ de grosor, muy erosionado. Uno presenta también cocción oxidante, y el otro oxidación incompleta. Por la cerámica en superficie se trataría de un sitio del Intermedio Tardío. Existe una vivienda encima del sitio arqueológico, la cual está destruyendo al mismo.

Nueva Huancabamba (My-019). Se ubica políticamente en la localidad de Nueva Huancabamba, en la margen derecha del río Huascayacu, afluente del río Mayo por su margen izquierda. El punto datum se ubica en las coordenadas UTM: $0266261 \mathrm{E}, 9356709 \mathrm{~N}$, y a $896 \mathrm{msnm}$. El asentamiento se encuentra emplazado sobre una pequeña colina natural de poca altitud, donde en la actualidad se cultiva café. El sitio arqueológico está conformado por dispersión de material cerámico localizado en la superficie del área. Se identificó abundante fragmentería cerámica en superficie, tanto diagnóstico como no diagnóstico, entre los cuales los más representativos corresponden a un fragmento de la parte superior de una vasija cerrada (olla), de $6 \mathrm{~mm}$ de grosor, cuello evertido externo, con cocción incompleta, de pasta anaranjado gris, presenta como técnica decorativa el escamado, que consiste en líneas diagonales. Hay otro fragmento con cocción reductora, de $5 \mathrm{~mm}$ de grosor, de pasta gris, presentando como técnica de manufactura el corrugado. Además de un fragmento de cocción reductora, pasta gris, de $9 \mathrm{~mm}$ de grosor, presenta una línea incisiva en la parte superior del tiesto. Por las características de la cerámica se trataría de un asentamiento del Intermedio Tardío. El sitio se encuentra en un mal estado de conservación.

Nueva Jaén (My-021). Se ubica en la localidad de Nueva Jaén, en la margen izquierda del río Mayo, sobre una ladera orientada hacia el norte. El terreno es de pendiente media. El sitio está afectado por una trocha carrozable; motivo por el cual se encuentran expuestos fragmentos de cerámica en superficie, cubierta de pastizales hacia el lado este, mientras que hacia el lado oeste se aprecian bosques con poca elevación. El punto datum se ubica en las coordenadas UTM: 0289647 E, 9342478 $\mathrm{N}$, y a $937 \mathrm{msnm}$. El sitio arqueológico está conformado por un área sin arquitectura, en la cual se encontró fragmentos de cerámica dispersas de manera heterogénea en la carretera. El material cerámico, tanto diagnóstico (de bordes evertido), presentan: técnica de manufactura en modelado y por corrugado; tipo de cocción: oxidante, oxidante incompleto y reductora; grosor: varia de 4 a 9 $\mathrm{mm}$; la pasta de dichos fragmentos está compuesto por elementos antiplásticos como, arcilla molida, restos orgánicos, cuarzo, mica, granos de piedras molidas, restos orgánicos; así como también asa con orientación vertical. Se halló también fragmentos no diagnósticos. El sitio corresponde al 
Intermedio Tardío. Se encuentra en mal estado de conservación, ya que solo se hace posible la visibilidad de los fragmentos de cerámica en el borde y en la misma carretera. El sitio arqueológico ha sido removido en gran parte para dar pase a la trocha carrozable, mientras a los extremos del sitio está cubierto de vegetación herbácea y boscosa.

En realidad aparte de estos sitios descritos, existe una gran cantidad de sitios con dispersión de cerámica por todo el territorio, los cuales en muchos casos no son visibles por estar cubiertos de una densa vegetación. Por referencia del Instituto Nacional de Cultura San Martín, se sabe que el proyecto Qapaq Ñan ha identificado sitios similares en Alfarillo, Ochamé, Naranjal, Santa Rosa de Oromina, San Mateo, Palmeras Oromina, Pascacio Noriega y El Milagro.

\section{INTERPRETACIONES CULTURALES}

\section{A. Patrón de asentamiento}

El patrón de asentamiento en la región de estudio es disperso, pues los sitios tardíos se hallan dispersos en el territorio, aunque cabe señalarse que existe una gran concentración de asentamientos en el Sector sur oriental del distrito de Moyobamba, como es en la localidad de Marona. Por las características topográficas de esta zona, ubicado en la margen derecha del río Mayo, en un área donde el valle se ensancha considerablemente, predominando tres áreas ecológicas bien definidas: la primera ubicada junto al río, conformado por un territorio plano, bajo e inundable en épocas de crecida, (actualmente cultivado de arroz); las zonas intermedias, conformadas por áreas de poca elevación conformado por el valle del río Marona y su delta; y por encima de esta se elevan los contrafuertes montañosos, de mayor pendiente y escarpados, los que llegan a alcanzar altitudes de hasta 1450 y $1500 \mathrm{msnm}$, ya dentro de los territorios de las actuales comunidades nativas protegidas. Las tres áreas, están conformadas por una densa y profunda acumulación geológica de depósitos de arcilla rojiza, con pequeños y aislados conglomerados rocosos. Es así, que por su naturaleza amplia y semiplana (en la segunda área), Marona ha sido un lugar apropiado para el asentamiento de pueblos y comunidades en periodos prehispánicos. Esto, aunado a las características empinadas y elevadas de los cerros aledaños, la amplitud de la quebrada de Marona, así como el cauce meándrico que hace el río Mayo en esta zona, habrían sido indicadores para el asentamiento de grupos poblacionales.

\section{B. Patrón arquitectónico}

El patrón arquitectónico en la zona está basado en el empleo de piedra como material constructivo, dispuestos en los muros en mamposterías con argamasa simple. Es posible hallar ciertas zonas rocosas en la localidad de Marona, como en El Milagro, que habrían cumplido la función de canteras para la extracción de piedras, siendo trasladadas para la edificación de estructuras. Sin embargo, es de suponer que por la exuberante vegetación arbórea, la madera se constituyó en un elemento constructivo muy común, hoy no identificado por el excesivo ambiente lluvioso y la naturaleza perecible de este producto. La estrategia constructiva en la zona, demandaba la edificación de terrazas consecutivas de poca o mediana altitud sobre las cuales se edificaban los recintos circulares, cuadrangulares o irregulares. La planta de las estructuras es principalmente circular u ovalada, de diferentes tamaños, de entre 2,50 y $9 \mathrm{~m}$ de diámetro. Estas estructuras serían más tardías y sería una influencia de la cultura Chachapoyas del territorio Andino. Existen también estructuras de planta rectangular o semi rectangulares que serían más tempranas, correspondientes a grupos locales. Es un patrón muy difundido la edificación de grandes canchones cuadrangulares, rectangulares o irregulares, los que presentan en sus esquinas internas, pequeños recintos de planta ovalada. Este sería el patrón de distribución de las unidades familiares para la región. 


\section{Cerámica}

La cerámica identificada en los sitios de la región tienen características propiamente amazónicas. Destaca la cerámica de manufactura corrugada, en considerable proporción. La cerámica de tipo corrugada, conocida en el Ucayali como Estilo Cumancaya. Lathrap (1970) define las características del estilo Cumancaya para el Ucayali, identificando dos tipos: el Cumancaya A que incluye las formas de vasijas simples de la tradición Pacacocha, así como adornos zoomórficos y corrugación; mientras que Cumancaya B incluye cuencos de base pedestal y pintura roja entre incisiones. Se ha identificado en Moyobamba fragmentería cerámica perteneciente a ambos tipos, especialmente en el sitio de San Lorenzo. Destacan fragmentos con decoración incisa lineal en diagonal, con pintura roja intermedia. La técnica de manufactura es por enrollado horizontal, utilizando arcillas roja, blanca y anaranjada. Pues el territorio de la cuenca del río Mayo está conformado por grandes depósitos arcillosos, no existiendo dificultad alguna para conseguir este material.

Entre las técnicas decorativas figuran: la incisión de líneas finas, rectas y geométricas; la pintura, utilizando principalmente los colores rojo (ocre y violáceo) y blanco, en algunos casos blanco sobre rojo; el digitado, técnica que consiste en la depresión o decoración obtenida por la presión del dedo sobre la vasija antes de la cocción; la aplicación, técnica mediante el cual se fijan o unen asas, soportes o cualquier proyección a la superficie de la vasija, se fija una o varias tiras o bolas de arcilla en la superficie de una vasija, siguiendo diversas formas y diseños; y el escamado, técnica decorativa en la que se emplea los dedos presionando la superficie aún fresca de la vasija, hundiendo la uña hacia el interior o con un instrumento plano cortante en forma diagonal y consecutiva por toda la superficie, quedando como resultado una impresión de escamas, similar a la de los peces. En el caso del corrugado, más que una técnica decorativa es producto de la manufactura, es el aspecto superficial resultante por la aplicación de las técnicas de enrollamiento y pellizcado, ósea que las tiras de barro que se sobreponen van dejando depresiones escalonadas. En algunos casos llevan impresiones de decoración y dentelladores como decoración. En el caso de todas estas técnicas decorativas, la dispersión en la vasija puede ser total o parcial.

Las formas identificadas son principalmente ollas medianas y pequeñas de cuello corto, algunas de cuerpo carenado y borde acomado o engrosado externo; así como cuencos altos y medianos. Se ha identificado también algunos fragmentos diagnósticos correspondientes a ollas de cuello corto y borde evertido, como el identificado en el sitio Bombonajal, lo que tendría influencia del Tahuantinsuyu. Anselmo Lozano (comunicación personal) nos refirió haber encontrado cerámica de influencia Tawantinsuyu en sus excavaciones en Chazuta (Tarapoto).

\section{CONCLUSIONES}

La región de estudio, presenta un paisaje amazónico, cubriendo una geomorfología aún andina. El río Mayo se desplaza serpenteante entre bajas colinas, que son los contrafuertes bajos de la cadena
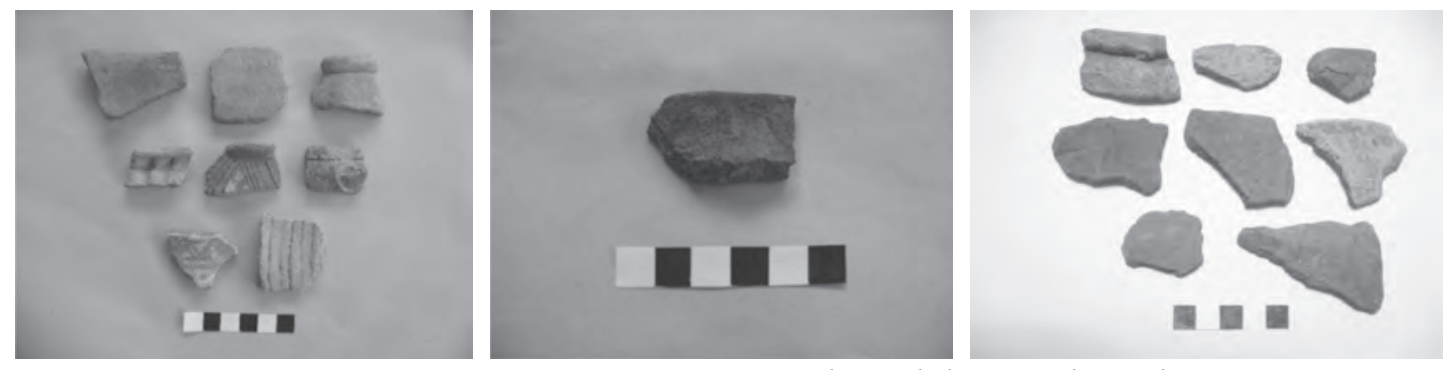

Figuras 3, 4 y 5. Fragmentos cerámicos procedentes de la región de estudio. 
oriental de los Andes, conformando un ecosistema andino-amazónico. De igual manera en lo cultural, la región ha recibido influencia de pueblos andinos y pueblos amazónicos, constituyéndose en una zona de interacción multicultural, como se ha evidenciado con la existencia de manifestaciones culturales de ambas regiones; pues así como encontramos cerámica típica de la región amazónica como la cerámica corrugada, tenemos también elementos andinos; además del quechua, la lengua hablada antes de la invasión española.

Esto nos lleva a plantear como hipótesis la existencia de cuatro grandes momentos culturales para esta región. Un primer momento temprano (equivalente al Periodo Lítico y Arcaico Andino), en el cual los grupos humanos tempranos que se desplazaban por la Amazonía, constituida en esos momentos en una sabana árida con refugios de bosques, transitaban por este territorio iniciando el ascenso a Los Andes por su lado oriental y luego manteniendo relaciones con los grupos amazónicos. Un segundo momento (contemporáneo con el Intermedio Temprano y Horizonte Medio Andino) caracterizado por la predominancia de grupos de características andinas, que habrían migrado desde los Andes. Un tercer momento, con predominanciade grupos amazónicos, quienes coexisten con los grupos del segundo momento. Mientras que un cuarto momento de predominancia andina, con la llegada de los grupos Chancas que se asentaron en la zona de Lamas, la presencia de grupos Chachapoyas y la anexión de este territorio al Tahuantinsuyu, lo que se vio truncado por la invasión española. Estas poblaciones, tanto en la Amazonía como andinas, no estuvieron estáticas, los desplazamientos poblacionales fueron continuos.

Los asentamientos se ubican sobre las terrazas aluviales medias del valle circundante a los ríos. La mayor concentración de asentamientos políticos de la zona se ubica en la localidad de Marona, pues se han identificado un Conjunto arqueológico con estructuras públicas (Mayumarca), un sitio ceremonial (El Templo), y cinco sitios domésticos (Marona, El Palto, El Pedregal, Marona Huayco y El Indomable). El sector de Marona se habría constituido en el área nuclear cultural de la localidad de Moyobamba, donde se habría encontrado el principal asentamiento político administrativo de la zona.

Las estructuras arquitectónicas presentan planta circular, de entre 5 y $12 \mathrm{~m}$ de diámetro en promedio, edificadas con piedras en la base, y posiblemente con madera y restos vegetales en la parte superior, hoy desaparecido por su naturaleza perecible. El patrón identificado para la zona de estudio señala la presencia de grandes canchones, en cuyas esquinas internas se aprecian recintos ovalados. También hay estructuras dispersas, que se trataría de viviendas rurales en el interior del bosque.

Sobre la entidad socio política que ocupó estos territorios antes de la llegada de los incas, las fuentes etnohistóricas nos señalan que habrían pertenecido a tres grupos, como son los orimonas,
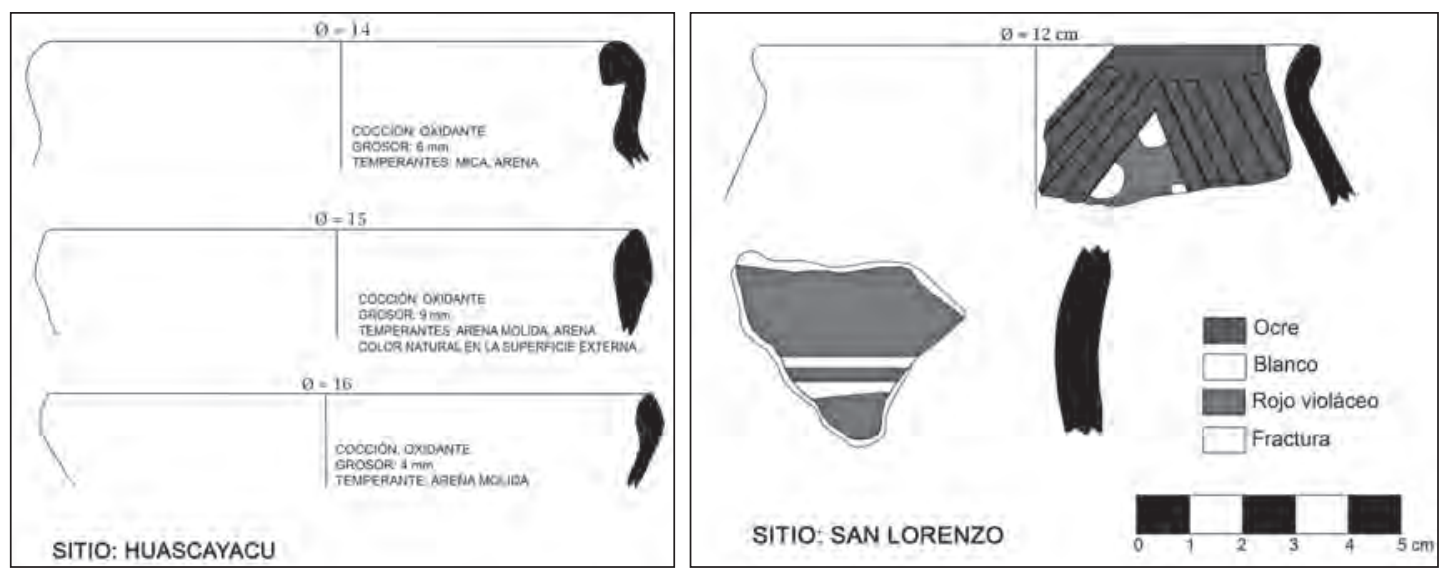

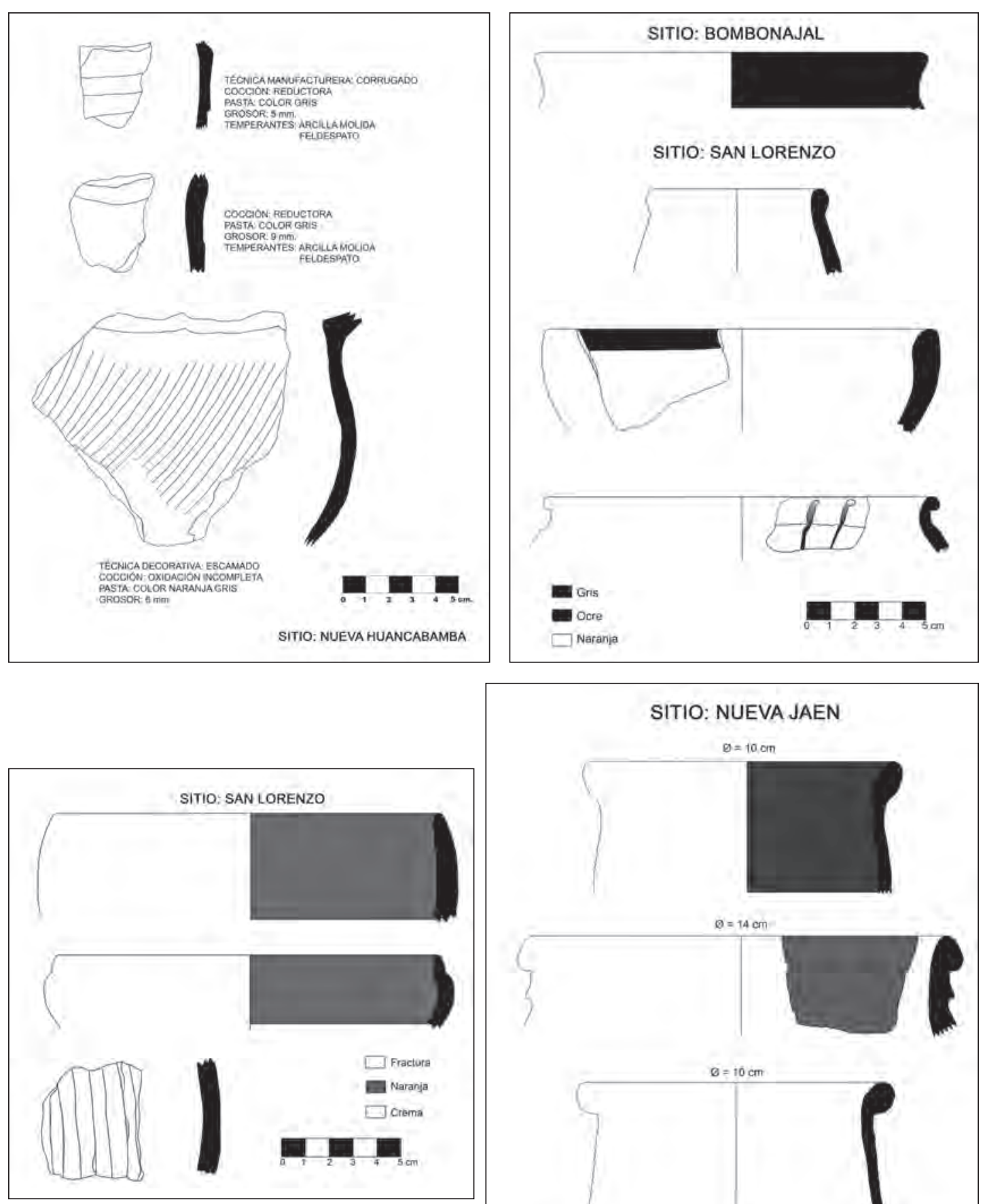

Figuras 6, 7, 8, 910 y 11. Formas cerámicas identificadas en los sitios mencionados en texto.

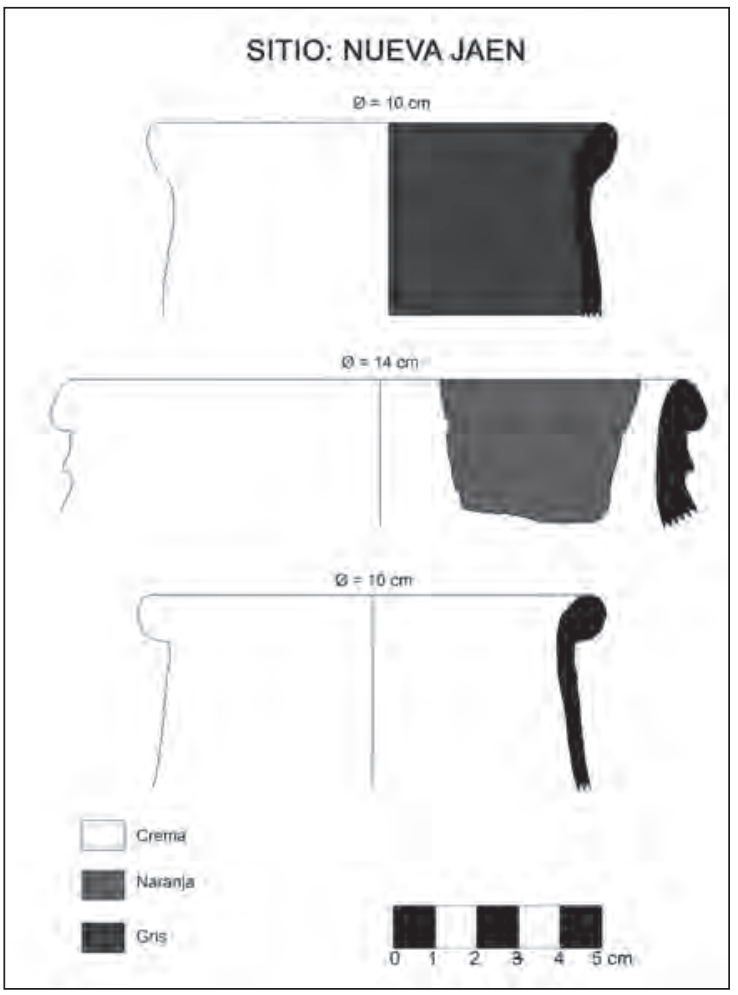


los posic y los ilacats. Sin embargo se piensa que estos habrían mantenido constantes relaciones con grupos Chachapoyas que habrían estado ingresando al bosque a modo de colonos con el fin de aprovechar recursos nativos (desarrollando un control vertical de pisos ecológicos), así como con los grupos Chancas que ingresaron aprox. hacia 1440 d.C. y se instalaron en la zona de Lamas y Tabalosos, los que eran conocidos como Motilones.

La conquista Inca habría sido casi pacífica, pues al saber de la derrota de los poderosos Chachapoyas, los demás grupos vecinos, no tan organizados militarmente, decidieron aceptar su integración al Tawantinsuyu. Sin embargo las fuentes etnohistóricas hacen referencia de que los Incas no lograron conquistar a los Orimonas, quienes ocupaban territorios más bajos.

\section{Reconocimientos}

Es necesario señalar que los trabajos referidos en el presente artículo fueron realizados en el marco del proyecto «Catastro, Titulación y Registro de tierras en los distritos de Moyobamba, río Tambo, Mazamari y San Martín de Pangoa, Selva del Perú», dentro del subcomponente de Identificación y Deslinde de Áreas Culturales intangibles. Nuestro trabajo en el distrito de Moyobamba se ejecutó entre los meses de octubre de 2008 y marzo de 2009 y fueron realizados en asistencia del Bach. Armando Gómez Valencia (UNSCH) y el Técnico GIS Bach. Jhonny Luque Huaquipaco (UNSA). 


\section{BiBLIOGRAFÍA}

BONAVIA, Duccio

1964 «Investigaciones en la Ceja de Selva de Ayacucho». En: arqueológicas 6. Instituto de Investigaciones Antropológicas, Museo Nacional de Antropología y Arqueología, Lima.

BUENO MENDOZA, Alberto

2008 «Investigaciones arqueológicas en el bosque de nubes» En: Amazonía Peruana XV(31): 365-400. LIma: Centro Amazónico de Antropología y Aplicación Práctica.

2009 «Arqueología de la cuenca del río Guabayacu, región San Martín, Perú». Investigaciones Sociales. 23: 15-58, Revista del Instituto de Investigaciones Histórico Sociales. Lima: Universidad Nacional Mayor de San Marcos (UNMSM).

BUENO, Alberto y Anselmo LOZANO

1982 «Pictografías en la cuenca del río Chinchipe» En: Boletín de Lima 20: 70-80, Marzo.

DEBOER, Warren R.

1975 «The archaeological evidence for manioc cultivation: a cautionary note». En: American Antiquity 40(4): 419-433. Washington.

1981 «Buffer zones in the cultural ecology of aboriginal Amazonia: an ethnohistorical approach». En: American Antiquity 46(2): 364-377. Washington.

1984 Archaeological reconnaissance in the central Huallaga, department ff San Martin, northeastern Perú. Department of Anthropology, Laboratory of Archaeology, Queens College, C.U.NY., Flushing, New York.

DEBOER, Warren; Eric ROSS, Jane y Maril VEALE

1977 «The Ceramic Collections from the rioHuasaga, Northen Peru: Their Place in the Prehistory of the Upper Amazon. En: El Dorado, II(2). Preeley: Museum of Antrhopology of Northen Colorado.

1981 «Pruebas arqueológicas del cultivo de yuca». En: Amazonía Peruana IV(2). Lima: CAAAP.

DEZA, Jaime

1975/76 «La Playa. Un complejo arqueológico en la cuenca del Abiseo». En: Boletín de Arqueología PUC 1718: 43-50. Lima: Pontificia Universidad Católica del Perú, Instituto Riva-Agüero (PUCP-IRA).

ECHEVARRÍA, Gori

2008 «Excavaciones arqueológicas en Chazuta, San Martín. Un reporte de campo (Primera temporada, 2002)». En: Amazonía Peruana XV(31): 323-341. Lima: Centro Amazónico de Antropología y Aplicación Práctica (CAAP).

ESPINOZA, Waldemar

2003 Juan Perez De Guevara y la historia de Moyobamba, siglo XVI. Lima: Derrama Magisterial.

LATRHAP, Donald

1958 «The cultural sequence at Yarinacocha, Eastern Perú». En: American Antiquity 23(4): 379-388. Salt Lake City.

1965 «Investigaciones en la selva peruana, 1964/1965». En: Boletín del Museo Nacional de Antropología y Arqueología. I(4): 9-12. Lima.

1968 «Aboriginal Occupation and Changes in River Channel on the central Ucayali, Perú». En: American Antiquity 33(1): 62-79. Salt Lake City.

1970 The Upper Amazon Ancient peoples and places. D. Glyn (ed.). Londres: Berkeley, Thames and Hudson.

1985 «La Antigüedad e importancia de las relaciones de intercambio a larga distancia en los trópicos húmedos de Sudamérica precolombina». En: Amazonía. Cerámica y rutas de intercambio: 49-62. Iquitos: Dirección Departamental del Ministerio de Industria, Turismo e Integración.

2010 El Alto Amazonas. S.R. Panduro (ed.). Lima: Instituto Cultural Runa. 299 p.

LOZANO, Anselmo

2002 Informe de la expedición multisectorial a la encañada del Tonchima, 6 y 7 de Mayo del 2002. Instituto Nacional de Cultura, departamental San Martin, Moyobamba, 18 p.

MAYER, Thomas

1967 «Reconocimiento arqueológico del Ucayali Central». En: Boletín del Museo Nacional de Antropologíay Arqueología 6. Lima. 


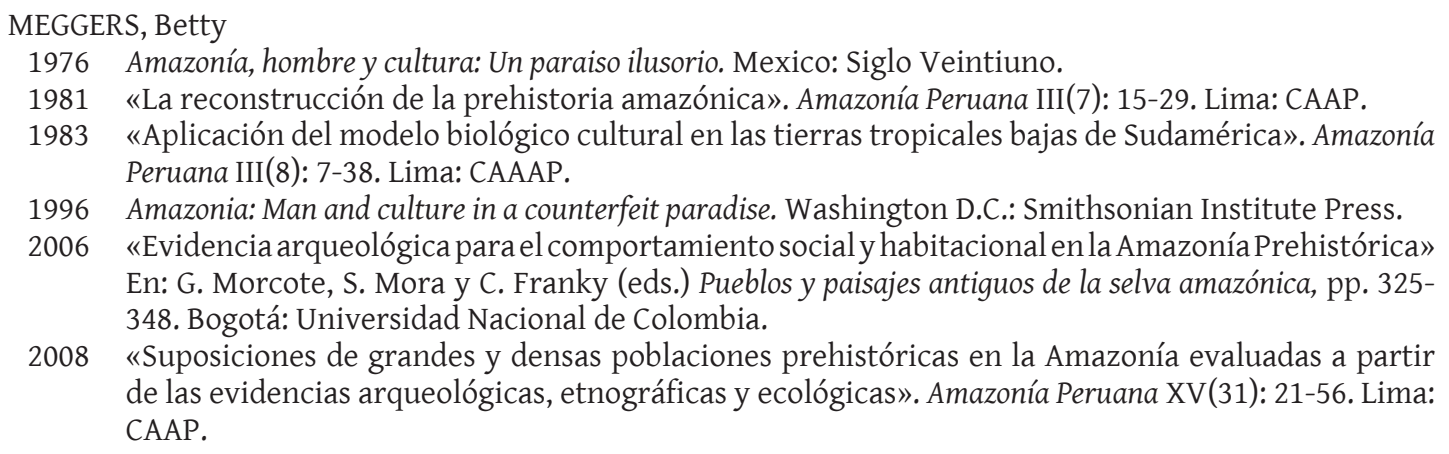

MILLA, Carlos

1977-1978 «Metodología para un catastro». En: Boletín del Seminario de Arqueología 19-20: 39-110. Lima: PCUP-IRA.

MORALES, Daniel

1989 «La selva 1,800 años antes de Cristo». En: Pura Selva 63: 18-20.

1992 «Chambira: Alfareros tempranos de la Amazonía peruana». En: D. Bonavia (Ed.) Estudios de Arqueología Peruana, pp. 149-176. Lima: Fomciencias.

1993 «Chambira: Alfareros tempranos de la Amazonía peruana». Separata del Centro de Estudiantes de Arqueología CEAR. Resumen de ponencia por la semana de Arqueología, 3 p.

1998a «Chambira: una cultura de sabana árida en la Amazonía Peruana». Revista de Investigaciones Sociales 2. Instituto de Investigaciones Histórico Sociales. Facultad de Ciencias Sociales, UNMSM.

1998b «Arqueología Amazónica del Perú». Apéndice. Historia arqueológica del Perú. Tomo I. Compendio Histórico del Perú. $2^{\circ}$ Edición. Lima: Milla Batres.

1999a «El desarrollo cultural de la Amazonía y su importancia». Resumen del curso intensivo de actualizacion en Historia Del Peru. UNMSM-MAA, febrero, 1 p.

1999b Dinámica demográfica y salud reproductiva en los grupos etnicos de la región Ucayali. Instituto de Investigaciones Histórico Sociales. Facultad de Ciencias Sociales, UNMSM. 37 p.

2008 «Reconstruyendo algunos aspectos socioculturales de artefactos excavados en el Bajo Ucayali, Perú». Amazonía Peruana XV(31): 211-250. Lima: CAAP.

OLIVERA, Quirino

2008 «Manifestaciones arqueológicas tempranas en el Alto Amazonas». Amazonía PeruanaXV(31): 303322. Lima: CAAP.

RAVINES, Roger

1995 «Cerámica antigua del Huallaga central, departamento de San Martín». Boletín de Lima 17(99): 16-22, julio-agosto. Lima.

RAYMOND, James; Warren DEBOER y Peter ROE

1975 Cumancaya: a peruvian ceramic tradition. Occasional Papers 2, Department of Archaeology. University of Calgary, Editorial Board.

VAN DALEN, Pieter

2009 Informe final del Proyecto de Catastro Arqueológico en el distrito de Moyobamba, Proyecto SNIP 13087, Titulación de la selva del Perú. Sub Componente de Identificación de Áreas Culturales. Informe COFOPRI. Moyobamba, 3 Tomos. 

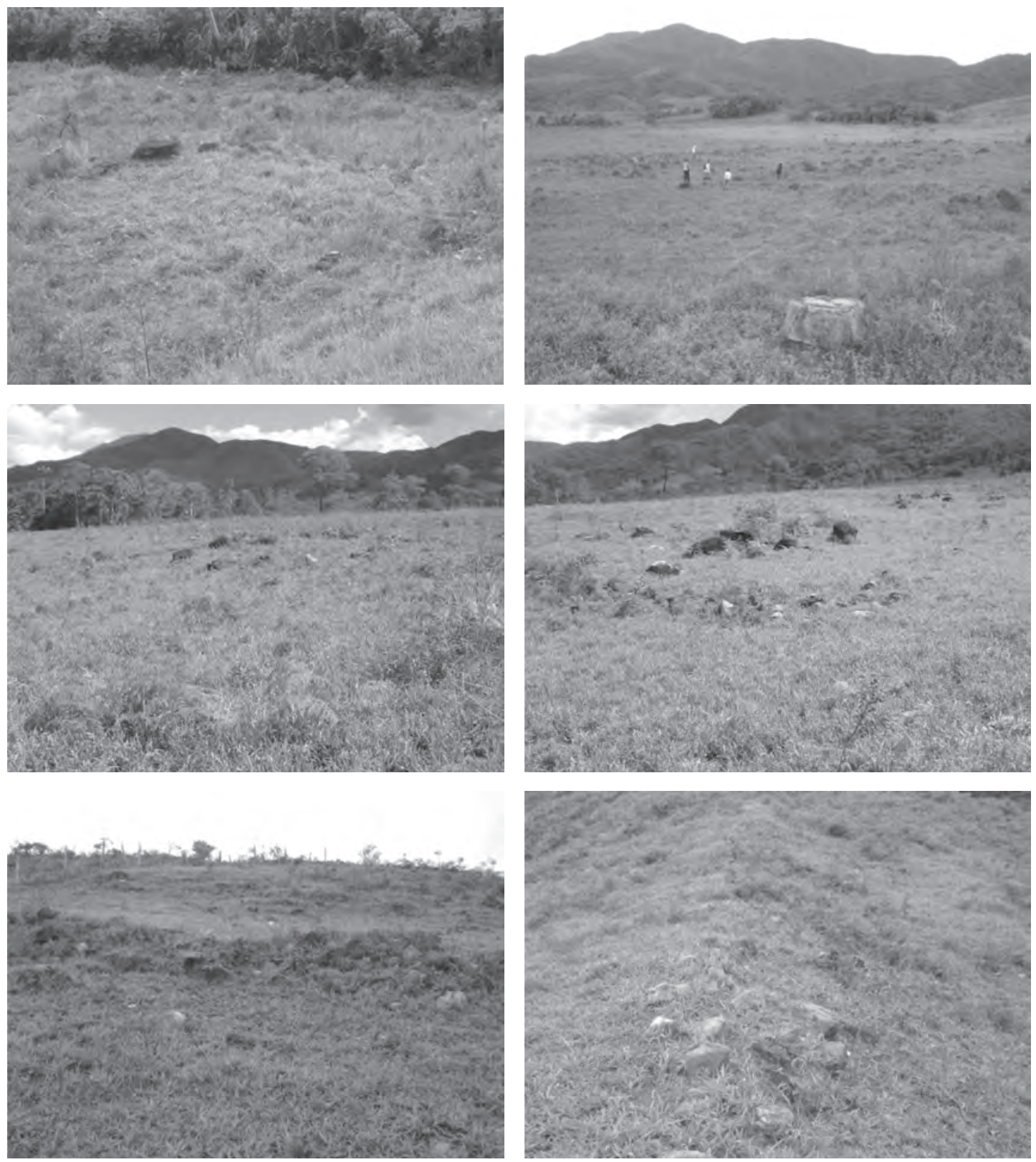

Figura 12 (Superior izquierda): Vista de recinto ovalado en sitio de Sarahuasi. Figura 13 (Superior derecha): Vista panorámica de Mayumarca. Figuras 14 y 15 (centro izquierda y derecha): Vista de recintos ovalados sitio El Palto. Figura 16 (inferior izquierda): Vista de las terrazas de Ginapata.

Figura 17 (inferior izquierda): Vista de la muralla de Marona. 


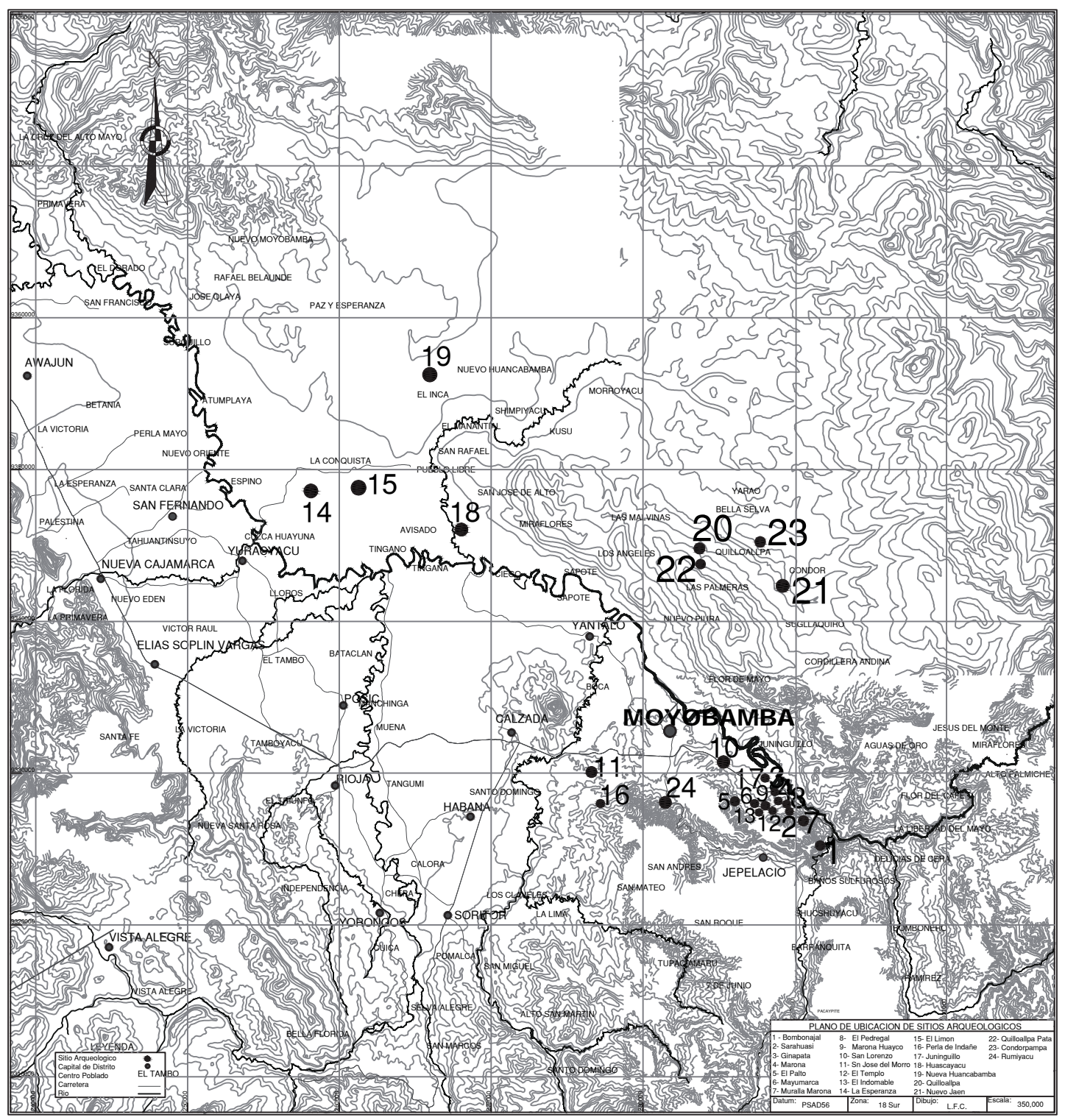

Figura 18: Plano de la cuenca media del río Mayo con la ubicación de los sitios mencionados en el texto. 